\title{
Surgery relieved symptoms but decreased survival more than medical treatment in gastro-oesophageal reflux disease
}

Sources of funding Department of Veterans Affairs Medical Research Service Cooperative Studies Program and Ethicon Endo-Surgery.

For correspondence: $\mathrm{Dr}$ SJ Spechler, Division of Gastroenterology (111B1), Department of Veterans Affairs Medical Center, 4500

South Lancaster Road, Dallas, TX 75216

USA.

sjspechler@aol.com.

Spechler SJ, Lee E, Ahnen D, et al. Long-term outcome of medical and surgical therapies for gastroesophageal reflux disease. Follow-up of a randomized controlled trial. JAMA 2001 May 9;285:2331-8.

\section{QUESTION: In patients with complicated gastro-oesophageal reflux disease (GORD), how do the long term outcomes of surgical treatment compare with those of medical treatments?}

\section{Design}

Randomised (allocation concealed*), blinded (unclear),* controlled trial with a mean follow up of 10 years.

Setting

8 Veterans Affairs medical centres in the US.

Surgical v medical treatment for complicated gastro-oesophageal reflux disease $\dagger$

\begin{tabular}{|c|c|c|c|c|}
\hline $\begin{array}{l}\text { Outcome during } \\
140 \text { months }\end{array}$ & Surgical & Medical & RBR $(95 \%$ Cl) $)$ & NNH (Cl)‡ \\
\hline Survival & $60 \%$ & $72 \%$ & $20 \%(0.5$ to 33$)$ & 7 (5 to 283 ) \\
\hline Outcomes at mean 10 year & & & $\operatorname{RRR}(\mathrm{Cl})$ & NNT (Cl) \\
\hline Any antireflux medication & $62 \%$ & $92 \%$ & $33 \%(17$ to 50$)$ & 4 (3 to 7$)$ \\
\hline Proton pump inhibitor use & $32 \%$ & $64 \%$ & $49 \%(21$ to 70$)$ & 4 (3 to 9$)$ \\
\hline Histamine-2-receptor blocker use & $41 \%$ & $65 \%$ & $37 \%(8.7$ to 60$)$ & $5(3$ to 20$)$ \\
\hline
\end{tabular}

†RBR = relative benefit reduction. Other abbreviations defined in glossary; RBR, RRR, NNH, NNT, and Cl calculated from data in article.

‡Calculated by using Cox proportional-hazards data.

\section{COMMENTARY}

Despite the advent of laparoscopic techniques, antireflux surgery is still a difficult procedure with uncertain long term outcomes. Antireflux surgery is a physiological repair of the oesophagogastric junction and involves 3 components: reduction of the hiatal hernia back into the abdomen, closure of the crura opening surrounding the oesophagus, and reinforcement of the lower oesophageal sphincter with a fundoplication. Furthermore, even a successful repair can "wear out" over time because the oesophagogastric junction continues to be exposed to repeated abdominal stressors, such as heavy isometric exercises or work-related activities, obesity, eating disorders, or recurrent vomiting and coughing.

The study by Spechler $e t$ al is the first long term study of antireflux surgery done outside a major oesophageal surgical centre in the US. The results are probably similar to the experience in our general communities. Despite this study, which used traditional open Nissen fundoplication surgery, current laparoscopic results do not appear to be any better. This study may suggest that antireflux surgery was a failure because $62 \%$ of patients returned to using medications for their GORD, and 32\% returned to using proton pump inhibitors. However, during the 9 years of follow up, $64 \%$ of patients treated with medications used proton pump inhibitors, whereas only $32 \%$ of the surgical group needed this expensive class of drugs. As the authors suggested, future studies will need to prospectively address the lower survival rate in the surgical treatment group $(60 \%)$ compared with that in the medical treatment group $(72 \%)$.

This important study may help to better define the role of antireflux surgery in the future treatment of GORD. It is not a cure for all patients and may have other still unknown disadvantages. However, some patients do well for a long time with minimal need for medication. Patients must understand the potentially beneficial and adverse effects of antireflux surgery and take part in this important treatment decision.

Joel E Richter, MD Cleveland Clinic Foundation, Cleveland, Ohio, USA

\section{Patients}

247 patients (mean age 58 y) with complicated GORD. 129 of 160 surviving patients (mean age $67 \mathrm{y}, 98 \%$ men) were included in the follow up analysis.

\section{Intervention}

Patients were allocated to receive surgical treatment $(n=82)$, continuous medical treatment $(n=77)$, or symptomatic medical treatment $(\mathrm{n}=88)$. The method of surgical treatment was open Nissen fundoplication. Continuous medical treatment consisted of 2 antacid tablets, 1 and 3 hours after meals; ranitidine $150 \mathrm{mg}$ twice daily; and metoclopramide $10 \mathrm{mg} 4$ times daily, and sucralfate $1 \mathrm{~g}$ in $10 \mathrm{ml}$ of warm water after meals, when necessary for persistent symptoms. Symptomatic medical treatment consisted of the above medications given only when necessary to control symptoms. Treatments were given for 12 to 28 months. Patients were then managed by their physicians.

\section{Main outcome measures}

Survival, use of antireflux medications, and frequency of subsequent antireflux surgeries.

\section{Main results}

Analysis was by intention to treat. The 2 medical treatment groups (continuous and symptomatic) were combined for analysis purposes because baseline characteristics, study treatments, and outcomes were similar. Survival during a period of 140 months was lower in the surgical group than the medical group $(\mathrm{p}=0.047)$ (table). Surgical treatment decreased the use of antireflux medications after the treatment period more than did medical treatment $(p \leqslant 0.02)$ (table). Surgical and medical treatments did not differ for use of prokinetics $(\mathrm{p}=0.39)$ or subsequent antireflux surgeries $(\mathrm{p}=0.38)$.

\section{Conclusions}

In patients with complicated gastro-oesophageal reflux disease, surgical treatment decreased survival and the use of antireflux medications more than did medical treatment. Surgical and medical treatments did not differ for subsequent antireflux surgeries.

*See glossary. 